\title{
Application and design of virtual reality technology in wellbore oil production process of pumping unit system
}

\author{
Tingting Liu ${ }^{1, a}$, Jiaheng $\mathrm{Wu}^{2, \mathrm{~b}}$, WeiXie ${ }^{1, \mathrm{c}}$, GangWu ${ }^{2, \mathrm{~d}}$, XueFeng $\mathrm{Jin}^{1, \mathrm{e}}$ Mengshi \\ Yang ${ }^{1, f}$, Zhixue Xia ${ }^{1, g}$,Yun Li ${ }^{1, h}$, Fang Li ${ }^{1, i}$, Penggang Chang ${ }^{1, j}$, \\ Lingbing Zeng ${ }^{1, k}$,Tingli Zhu ${ }^{3,1}$ \\ ${ }^{1}$ Huabei Oil Field Production Technology Research Institute Renqiu ,Hebei 062552,China \\ ${ }^{2}$ HuaBei Oil Field Oil Production Plant No 1, Renqiu ,Hebei 062552,China \\ ${ }^{3}$ HuaBei Oil Field Technical Supervision And Inspection Department, Renqiu ,Hebei 062552,China \\ acyy_liutt@petrochina.com.cn, bcy1_wjheng@petrochina.com.cn, ccyy_xiew@petrochina.com.cn, \\ dcyy_wug@petrochina.com.cn, ecyy_jinxf@petrochina.com.cn, 'cyy_yangms@petrochina.com.cn, \\ 9cyy_xiazx@petrochina.com.cn, hcyy_liy@petrochina.com.cn, 'cyy_changpg@petrochina.com.cn, \\ jcyy_lif@petrochina.com.cn, kcyy_zenglb@petrochina.com.cn, yjzx_ztl@petrochina.com.cn
}

Key words: Virtual Reality ; Computer Aided Designing; Simulation; Visualization;

Abstract:This paper describes the virtual simulation system based on digital computation aided design (CAE) and visual simulation technology. The pumping unit wellbore $3 \mathrm{~d}$ visualization platform developed by this system can display the three-dimensional wellbore track, simulate the three-dimensional wellbore work string statically, simulate real motion and the whole life cycle of wellbore string by establishing a dynamic three-dimensional model . Using virtual reality technology can realize the total life cycle management of oil well such as optimization design of producing wells , the construction risk assessment, dynamic analysis and prediction of the operation process. This technology is of great significance to guide the design of construction parameters of the wellbore rod and pipe string.

\section{Introduction}

Virtual reality technology is one of the frontier research fields in contemporary information science. It combines computer graphics, computer visual, psychology, artificial intelligence, sensor and network communication, and other aspects of technology. It creates a virtual environment in the computer. It makes users to produce immersive real sense through real-time, three-dimensional graphics display, sound simulation, human and virtual environment of natural real-time interaction. At present, virtual reality technology has become an important technical means and tools in the whole life cycle of the system.

\section{Simulation Model}

Simulation model of axial vibration and axial movement of sucker rod string.

The wave equation of axial vibration of sucker rod string is described:

$$
\left\{\begin{array}{l}
\rho_{\mathrm{r}} A_{\mathrm{r}} \frac{\partial^{2} u}{\partial t^{2}}-E_{\mathrm{r}} A_{\mathrm{r}} \frac{\partial^{2} u}{\partial x^{2}}+v \frac{\partial u}{\partial t}+\delta h N=\rho_{\mathrm{r}}^{\prime} A_{\mathrm{r}} g \cos \theta-\rho_{\mathrm{r}} A_{\mathrm{r}} \frac{\partial^{2} u_{0}}{\partial t^{2}}-v \frac{\partial u_{0}}{\partial t}+\delta(x-L) P_{p}(t) \\
N=\sqrt{\left(P \frac{d \theta}{d x}-q_{r} \sin \theta\right)^{2}+\left(P \sin \theta \frac{d \varphi}{d x}\right)^{2}}
\end{array}\right.
$$

Where

$$
\rho_{\mathrm{r}}^{\prime}=\rho_{\mathrm{r}}-\rho_{\mathrm{L}}
$$


$v$ is damping coefficient of wells liquid to sucker rod column, $1 / \mathrm{s} ; \rho_{\mathrm{r}}$ is density of rod material, $\mathrm{kg} / \mathrm{m} 3 ; \rho_{\mathrm{L}}$ is density of well liquid, $\mathrm{kg} / \mathrm{m}^{3} ; \mathrm{E}_{\mathrm{r}}$ is elastic material of sucker rod material, $\mathrm{N} / \mathrm{m}^{2} ; \mathrm{A}_{\mathrm{r}}$ is the cross-sectional area of the sucker rod, $\mathrm{m}^{2} ; \theta$ is wells angle; $\psi$ is hole azimuth angle; $\mathrm{P}$ is axial force, $N$; $h$ is coefficient, $h=f / A_{r}{ }^{*} \rho_{r} ; f$ is friction coefficient between rod and tube; $u^{*}(t)$ is motion displacement of suspension point, $\mathrm{m} ; \mathrm{P}_{\mathrm{p}}$ is the liquid load on the pump plunger, $\mathrm{N} ; \delta$ is a Coefficient, depending on the direction of the motion of the pumping rod.

At present, more than $90 \%$ international mechanical products and equipment are analyzed by using finite element method. The basic idea of the finite element method for sucker rod is that at first disperse the suck rod string into a number of spatial beam element, and then establish the element equilibrium equation with any single beam unit as the research object based on the principle of virtual work, finally establish the whole equilibrium equation of the sucker rod string through the whole stiffness matrix and load matrix.It is shown in figure1.

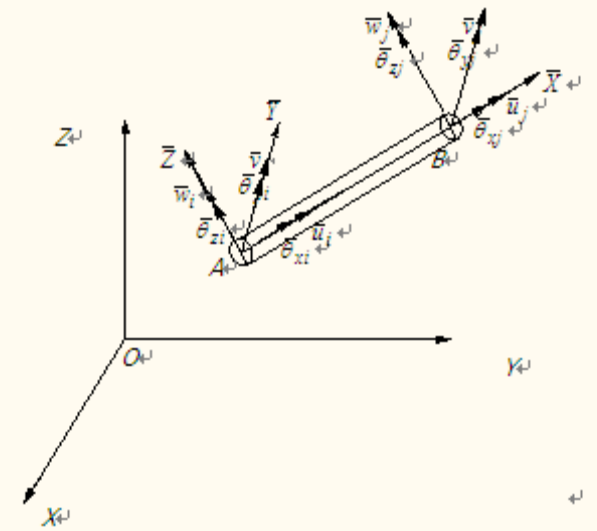

Fig. 1 node displacement and diagram of space beam element

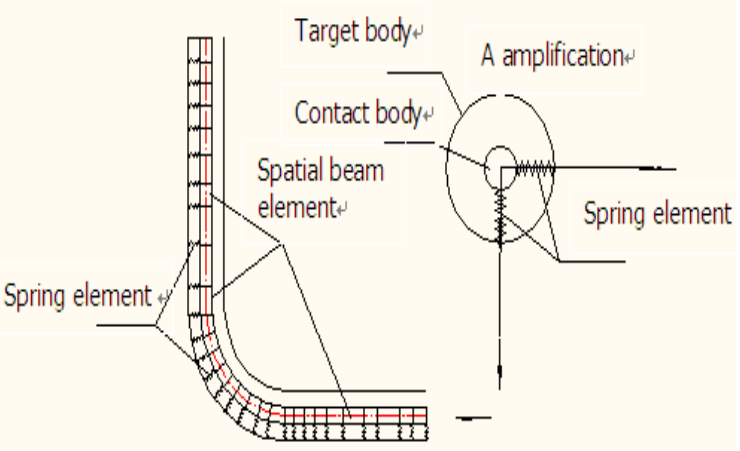

Fig. 2 schematic diagram of space beam element

The basic idea of the spring element method is that at first disperse target sucker rod into a number of spatial beam element with the general finite element method, and then place two spring element which are convenient and accurate simulation of rod and pipe contact state along the element local coordinate system $\mathrm{y}$ axis and $\mathrm{Z}$ axis, finally nonlinear mechanical problems of rod and pipe contact are solved by the spatial beam element and spring element combination .

On the basis of the general finite element method, the space beam element and spring element assembled is shown in figure2.

\section{Pumping wellbore 3D visualization platform based on VR Technology}

Development model and Platform architecture.System uses B/S+C/S mixed development model and the current popular.NET development platform for the development of the project. Platform have typical three layer structure which are the interface presentation layer, business logic layer, model data layer. Multi core integration management mode, each core to complete the independent function of the virtual simulation system, the core of the integration through the database technology to achieve the unified management and call of the system. platform architecture is shown in figure 3 . 


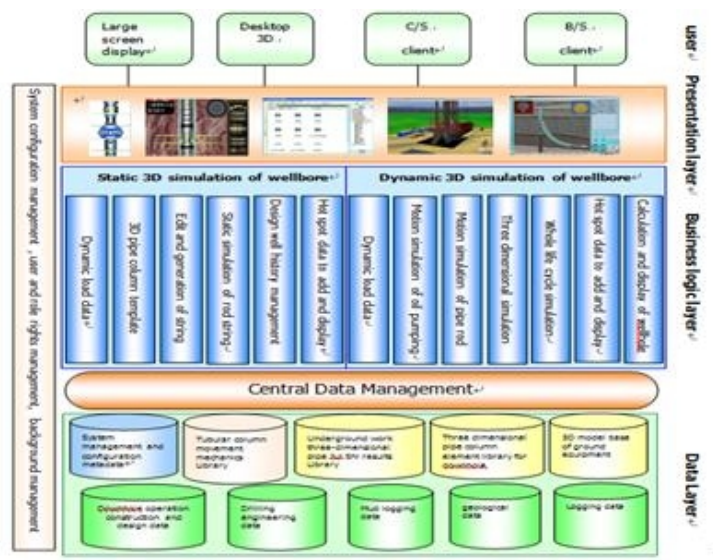

Fig .3 software layered architecture diagram

Major function.The main functions of the system are divided into three parts: static 3D simulation of wellbore, Dynamic 3D simulation of wellbore.

Static 3D simulation of wellbore based on the Virtools platform development, combining VSL script programming language and SDK software development package to realize the 3D well trajectory generation, tools and components edition, including tool drag, rotate and zoom, synchronous display function, including: well trajectory data information (sounding, deviation angle, azimuth angle, full width change rate), based data information (types of tools, specific parameters, etc.). It is shown in figure 4.

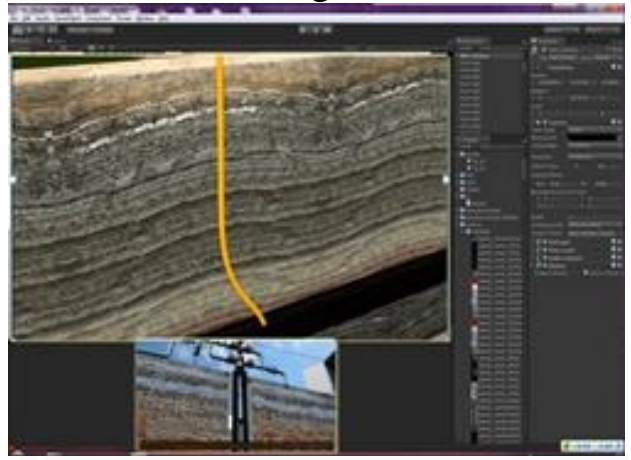

a display of 3D well trajectory scale

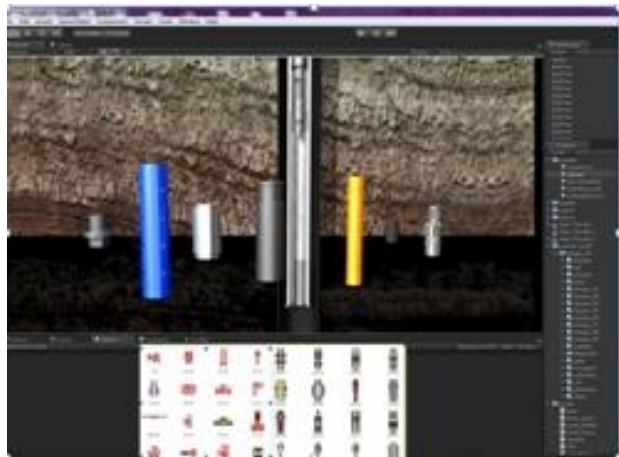

b sketch map of 3D edit of process pipe column

Fig. 4 sketch map of 3D static simulation of wellbore

Dynamic 3D simulation of wellbore use Virtools to connect the Oracle database through the VT Server, the extracted wellbore motion data is used to drive the periodic movement of the shaft, and the simulation of the dynamic simulation of the three-dimensional wellbore pipe column is simulated. Including the simulation of motion process of the fluid in the wellbore, string motion of eccentric wear, bending, distortion, simultaneous display function well trajectory data information (sounding, deviation angle, azimuth angle, full width change rate), based data information(types of tools, specific parameters, etc.) and pressure data information of tube rod string . It is shown in figure 5.

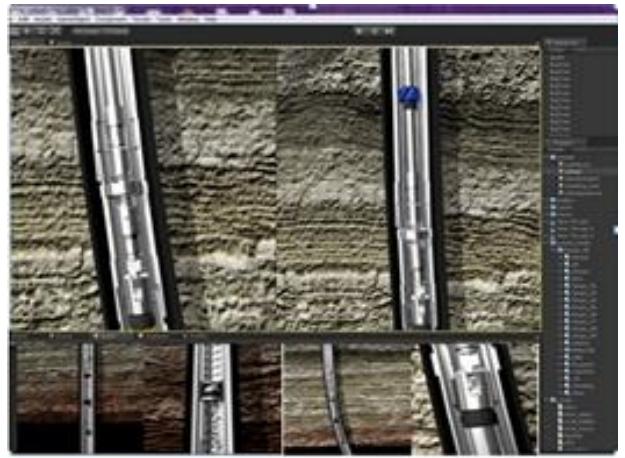

a schematic diagram of stress deformation

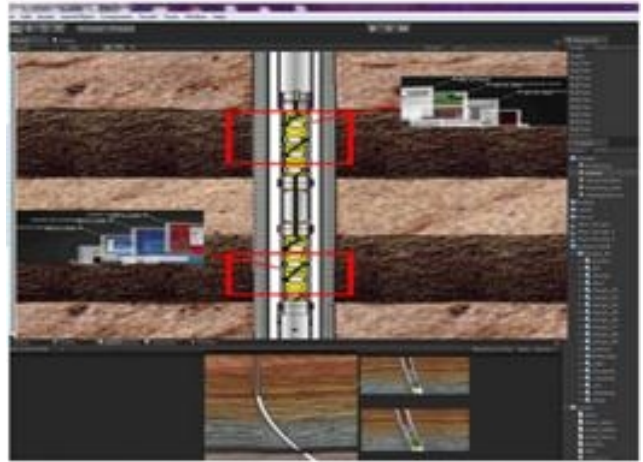

b schematic diagram of hot spot data

Fig. 5 sketch map of 3D dynamic simulation of pumping unit 


\section{Application examples.}

As a guide pipe the rational selection of the parameters for the design and construction of rod string, by pumping oil wells virtual reality digital simulation system of Huabei Oilfield 10 wells are mechanical simulation calculation and the whole well deflection proof and abrasion proof analysis, the results carries on the comparison between the simulation result and the actual operating records are shown in Table 1. The system runs stably, the operation efficiency is high, the operation result conforms to the rate reach to $93.7 \%$, the fault rate is 0 .

Table 1 The comparison between the simulation result and the actual operating records

\begin{tabular}{|c|c|c|c|c|}
\hline Well No & Calculation module & Calculation of eccentric wear & Eccentric wear & Actual operation situation \\
\hline \multirow[b]{2}{*}{ Test $25-14$} & Axial force calculation & $1600-1800$ & serious & \multirow{2}{*}{$\begin{array}{l}\text { 1、 tubing placement } 1458-1719 ; \\
\text { sucker rod replacement } 913-1737 ; \\
\text { Sucker rod broken } 1489 \\
\text { 2、 tubing placement } 18-261 \text {, sucker } \\
\text { rod replacement } 849-1801 \text {, Sucker } \\
\text { rod broken } 1489\end{array}$} \\
\hline & Radial force calculation & $375-1550$ & Not too serious & \\
\hline \multirow[b]{2}{*}{ Test $25-15 \mathrm{X}$} & Axial force calculation & 1674-1988 & serious & \multirow{2}{*}{$\begin{array}{l}\text { 1、 tubing placement } 1359-1710 \text {, } \\
\text { sucker rod replacement } 889-1713 \\
\text { 2、 tubing placement } 1917-2025 \text {, } \\
\text { sucker rod replacement } 862-1702\end{array}$} \\
\hline & Radial force calculation & $374-1599$ & Not too serious & \\
\hline \multirow{2}{*}{ Test 25-18X } & Axial force calculation & $1699-1924$ & serious & \multirow{2}{*}{$\begin{array}{l}\text { 1、 tubing placement } 18-279 \text {, sucker } \\
\text { rod replacement } 317-409\end{array}$} \\
\hline & Radial force calculation & $400-1649$ & Not too serious & \\
\hline \multirow{2}{*}{ Test 31-14X } & Axial force calculation & $1624-1874$ & serious & \multirow{2}{*}{$\begin{array}{l}\text { 1、 pinch off } 1121, \text { sucker rod } \\
\text { replacement } 1121-1129\end{array}$} \\
\hline & Radial force calculation & $349-1524$ & Not too serious & \\
\hline \multirow{2}{*}{ Test $11-25$} & Axial force calculation & $1625-1850$ & serious & \multirow{2}{*}{$\begin{array}{l}\text { 1、Sucker rod broken } 1565 \text {, sucker } \\
\text { rod replacement } 845-997 、 1414-1862\end{array}$} \\
\hline & Radial force calculation & $125-1500$ & Not too serious & \\
\hline \multirow{2}{*}{ Test $11-28$} & Axial force calculation & $725-1225$ & serious & \multirow{2}{*}{$\begin{array}{l}\text { 1、 rod deformation } 888-912 \text {, sucker } \\
\text { rod replacement } 1212-2308\end{array}$} \\
\hline & Radial force calculation & $1275-2175$ & Not too serious & \\
\hline \multirow[b]{2}{*}{ Test $22-17$} & Axial force calculation & $1600-1700$ & serious & \multirow{2}{*}{$\begin{array}{l}\text { 1、 tubing placement } 753-1823 \text {, sucker } \\
\text { rod replacement } 444-1790 \\
\text { 2、 tubing placement } 1204-1786 \text {, } \\
\text { sucker rod replacement } 1135-1175 \text { 、 } \\
1745-1785\end{array}$} \\
\hline & Radial force calculation & $400-1500$ & Not too serious & \\
\hline \multirow[b]{2}{*}{ Test 22-32 } & Axial force calculation & $1120-1245$ & serious & \multirow{2}{*}{$\begin{array}{l}\text { 1、 tubing placement } 532-1303, \\
\text { sucker rod replacement } 655-1303 \text {, } \\
\text { Sucker rod broken } 1015 \\
\text { 2、 tubing placement } 722-1302, \\
\text { sucker rod replacement } 30-1142 \\
\end{array}$} \\
\hline & Radial force calculation & $145-1095$ & Not too serious & \\
\hline \multirow{2}{*}{ Test 22-35 } & Axial force calculation & $1500-1975$ & serious & \multirow{2}{*}{ 1、 release of eccentric wear 1574} \\
\hline & Radial force calculation & $225-1175$ & Not too serious & \\
\hline \multirow[b]{2}{*}{ Test $814 \mathrm{X}$} & Axial force calculation & $325-1050$ & serious & \multirow{2}{*}{$\begin{array}{l}\text { 1、 tubing placement } 426-906 \\
\text { 2、 tubing placement } 330-906 \text {, sucker } \\
\text { rod replacement } 800-906\end{array}$} \\
\hline & Radial force calculation & $525-900$ & Not too serious & \\
\hline
\end{tabular}

\section{Conclusion}

The virtual simulation system which based on digital computing aided design (CAE) and the scene simulation of composite technology, finally establishes the digital simulation laboratory of mechanics through macro digital simulation and the micro rod and tube for the finite element analysis. Based on oil pumping machine, gas storage well bore research, it gradually realizes the production wells optimization design, risk assessment, dynamic prediction, accident reconstruction, and so production nodes of digitalization, visualization, and inallyrealized based on the virtual reality technology of oil and gas wells in the whole life cycle management, prediction and optimization through the late supplement other simulation models (such as injection, fracturing, overhaul and operation). 


\section{Acknowledgements}

This work was financially supported by the Huabei Oil Field Production Technology Research Institute Municipal Education Commission of RenQiu (062252).

\section{Reference}

[1] Xianmei Liu, Qin Li, Guohai Si, Xuesong Chen . Virtual reality technology and its application [J]. Journal of Daqing Petroleum Institute 2002,26 (2): 112-115.In Chinese.

[2] Xianme Liu i, Fei Gao . Virtual simulation system for oil field drilling [J]. computer system application, 2012,21 (7): 5-8. In Chinese.

[3] Biao Sun, Lixue Chen . Computer simulation technology in petroleum industry in the application [J]. Journal of Southwest Petroleum Institute.1999.19 (1): 88-92. In Chinese.

[4] Xiushan Zhang, Ronghua Xu, Qingfeng $\mathrm{Hu}$. Virtual reality technology and programming skills [M]. Changsha: National University of Defense Technology press, 1999.52-54. In Chinese.

[5] Xianmei Liu , Shiguang Sun . Design and implementation of simulation training system based on [J]. Virtools computer technology and development 2013 (11): 209-212. In Chinese. 